\title{
Comparison of cathodal, anodal, and bipolar strength-interval curves with temporary and permanent pacing electrodes ${ }^{1}$
}

\author{
RAHUL MEHRA AND SEYMOUR FURMAN \\ From the Cardiothoracic Service, Division of Surgery, Montefiore Hospital and Medical Center, Bronx, \\ New York, USA
}

SUMMARY Acute animal experiments indicate that ventricular vulnerability to fibrillation or multiple premature contractions is greater during bipolar or anodal stimulation than with unipolar cathodal (with electrodes of equal cathodal and anodal surface area) because the anodal and bipolar absolute refractory periods are shorter, enabling easier excitation in the vulnerable period. To compare the relative safety of stimulation with various commercial electrodes, strength-interval curves were determined in patients during the initial period after electrode implantation (acute studies) and after a few years of pacing (chronic studies). In 9 of 10 acute studies in patients with permanent bipolar electrodes (anode surface area 4.4 times cathode) and in 9 of 10 chronic studies in patients with bipolar electrodes, the unipolar cathodal and bipolar refractory periods were equal. However, in 7 of 12 patients with temporary bipolar electrodes (equal anodal and cathodal surface areas) and in 2 out of 20 acute and chronic studies in patients with permanent bipolar electrodes, the bipolar refractory periods were significantly shorter than cathodal because of anodal stimulation at the proximal electrode. Under appropriate physiological conditions and competitive pacing, these patients would be more vulnerable to arrhythmias with bipolar stimulation than with unipolar cathodal. To decrease that risk, the anodal surface area should be 5 to 7 times the cathodal, or the anode should be removed from the ventricle, especially for temporary pacing in circumstances of high vulnerability to arrhythmias.

Arrhythmias initiated by electrical stimulation of the heart have been well documented in animals and in man (Wiggers and Wegria, 1940; Brooks et al., 1955; Bilitch et al., 1967). The probability of occurrence of pacemaker induced ventricular fibrillation or tachycardia is small but increases in the presence of specific physiological and pharmacological factors and during stimulation about the $T$ wave and in patients with bipolar as compared with unipolar electrodes (Preston, 1973). The electrophysiological basis for the differences in arrhythmia susceptibility with unipolar cathodal, unipolar anodal, and bipolar stimulation has been shown in animals to result from the dissimilarities in the maximum prematurity of stimulation that can occur (Mehra et al., 1977). In an acutely ischaemic ventricle, the vulnerable period for fibrillation or multiple premature contractions

${ }^{1}$ Supported in part by a U.S. Public Health Service Grant. Received for publication 25 April 1978 starts at the end of the absolute refractory period and ends at a certain time thereafter. As the refractory periods with anodal and bipolar stimulation are shorter than with cathodal (when equal surface area cathode and anode are used), a response is possible earlier in the cardiac cycle with anodal or bipolar stimuli and their vulnerable periods are, therefore, longer.

In the present study, we evaluate the possible clinical differences between cathodal and bipolar stimulation in relation to ventricular vulnerability. Despite the prevalence of non-competitive pacing, circumstances arise because of pacemaker malfunction or during acute myocardial infarction (Chatterjee et al., 1970) when competition between pacemaker stimuli and spontaneous cardiac rhythm occurs.

To compare the maximum prematurity of stimulation possible with unipolar cathodal, unipolar anodal and bipolar stimuli, the cardiac excitation threshold was measured during the cardiac cycle, 
and strength-interval curves were plotted, in patients with intracardiac electrodes. Two studies were undertaken. In the first, unipolar cathodal and anodal strength-interval curves were compared. Though unipolar anodal stimulation is not used clinically, these data helped to explain the effect of the inadvertent unipolar anodal stimulation that can occur during temporary pacing. In the second study, bipolar and unipolar strength-interval curves were compared.

\section{Patients and methods}

Strength-interval curves were derived for different modes of stimulation (Fig. 1) in 43 paced patients. Informed consent was obtained from all patients. Extremely sick patients and those suffering from acute myocardial infarction were excluded from the study. The 'acute studies' were performed with implantable (permanent) electrodes at the time of insertion and with 'temporary' electrodes at insertion or within a few days thereafter. The 'chronic studies' were made on patients with electrodes in use for between 1 and 5 years, during pulse-generator replacement. The electrodes were

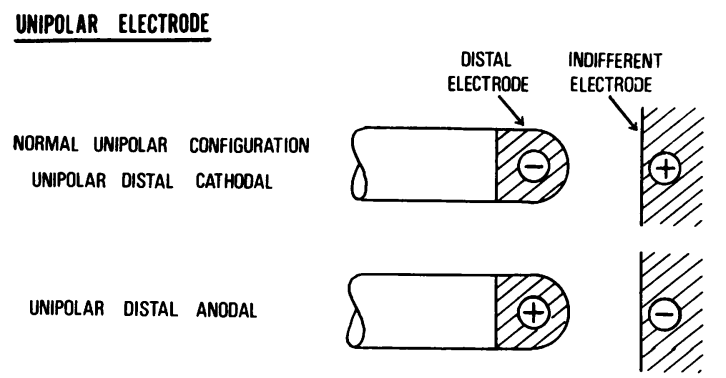

\section{BIPOLAR ELECTRODE}

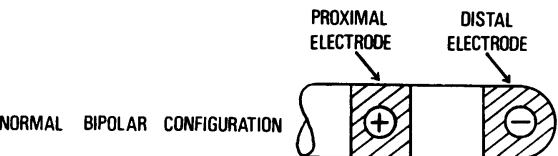

UNIPOLAR DISTAL CATHODAL
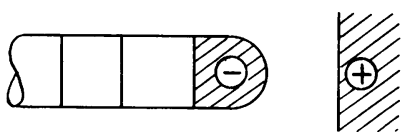

UNIPOLAR PROXIMAL ANODAL
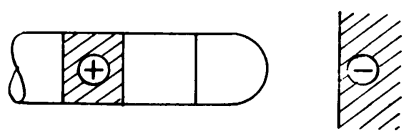

Fig. 1 Different modes of stimulation for which the strength-interval curves were determined with unipolar and bipolar electrodes. either unipolar or bipolar and differed in the stimulating surface areas (Table 1). During unipolar stimulation with an implantable electrode, the subcutaneous pulse generator site was used for the indifferent electrode while for the temporary electrodes, a surgical steel wire inserted in the skin of the right pectoral region acted as the indifferent electrode.

Most patients were paced at 80 beats/minute via their right ventricular electrodes. In some the pacing rate was 90 to 100 beats per minute to eliminate competition. Cathodal pacing at twice the current excitation threshold was used for all studies with the test pulse occurring every seventh beat. From the normally excitable period, the test pulse delay was progressively shortened in $20 \mathrm{~ms}$ steps and at each stimulus interval the cathodal, anodal, or bipolar threshold of excitation was measured to an accuracy of $0.1 \mathrm{~mA}$. As the stimulation threshold rose during the relative refractory period, steps of $10 \mathrm{~ms}$ duration or less were used. To measure threshold, the test pulse was progressively decreased in amplitude with two applications of the test pulse at each current. Threshold was the minimum test current which, during each of its two applications, resulted in a captured beat. The stimulator ${ }^{1}$ delivered constant current pulses of $1.0 \mathrm{~ms}$ duration with a maximum output of $9 \mathrm{~mA}$. Resuscitation equipment was always kept available in case of any serious arrhythmias.

\section{Results}

(a) UNIPOLAR CATHODAL AND ANODAL STRENGTH-INTERVAL CURVES

Unipolar cathodal and anodal strength-interval curves were plotted in 8 acute and 9 chronic cases (Fig. 2 and 3 ). In the acute studies, the refractory periods for anodal stimulation were usually shorter than for cathodal at most stimulus currents, while in the chronic studies the anodal refractory periods were usually longer. However, in one acute study, the cathodal refractory period was shorter than anodal at lower stimulus currents (Fig. 2b), and in 2 chronic studies, the anodal refractory periods became shorter at higher stimulus currents (Fig. 3b). In both acute and chronic studies, the mean difference in refractory periods was expressed as a function of current density rather than stimulus current so that it was possible to compare electrodes of different surface area (Table 2). In the acute studies the difference in refractory periods averaged 7 to 9 milliseconds at most current densities. In the chronic studies the anodal refrac-

${ }^{1}$ Devices Sales Ltd, Hertfordshire, England 
Table 1a Electrodes used for determining unipolar distal cathodal and anodal strength-interval curves

\begin{tabular}{lllll}
\hline & Manufacturer & Electrode type & Distal area $\left(\mathrm{mm}^{2}\right)$ & No. of cases \\
\hline (1) Acute & $\begin{array}{l}\text { Medtronic } \\
\text { Medtronic }\end{array}$ & 6907 & 11 & 5 \\
& & 6901 & 11 & -3 \\
& & & - & 8 \\
(2) Chronic & Cordist & $2 \mathrm{~mm}$ & 12 & 5 \\
& Medtronic & 6901 & 11 & 1 \\
& Medtronic & 5819 & 11 & 1 \\
& Cordis & $4 m m$ & 85 & 1 \\
& Medtronic & 5816 & & 9 \\
\hline
\end{tabular}

Table 1b Electrodes used for determining bipolar, unipolar distal cathodal, and unipolar proximal anodal strength-interval curves

\begin{tabular}{|c|c|c|c|c|c|}
\hline & Manufacturer & Electrode type & Distal area $\left(\mathrm{mm}^{2}\right)$ & Proximal area $\left(\mathrm{mm}^{2}\right)$ & No. of cases \\
\hline (1) Acute & $\begin{array}{l}\text { Medtronic } \\
\text { Cordis }\end{array}$ & $\begin{array}{l}\text { 6901 } \\
\text { Temp. }\end{array}$ & $\begin{array}{l}11 \\
12 \cdot 5\end{array}$ & $\begin{array}{l}48 \\
12 \cdot 5\end{array}$ & $\begin{array}{l}10 \\
\frac{12}{22} \\
-\end{array}$ \\
\hline (2) Chronic & $\begin{array}{l}\text { Medtronic } \\
\text { Medtronic } \\
\text { GE } \ddagger \\
\text { Medtronic }\end{array}$ & $\begin{array}{l}6901 \\
5819 \\
\text { A2070 } \\
5816\end{array}$ & $\begin{array}{l}11 \\
11 \\
11 \\
85\end{array}$ & $\begin{array}{l}48 \\
48 \\
43 \\
80\end{array}$ & $\begin{array}{r}5 \\
1 \\
2 \\
2 \\
-10 \\
-\end{array}$ \\
\hline
\end{tabular}

$\star$ Medtronic Inc., Minneapolis, Minn.

† Cordis Corp., Miami, Florida

¥ General Electric Co., Milwaukee, Wisconsin

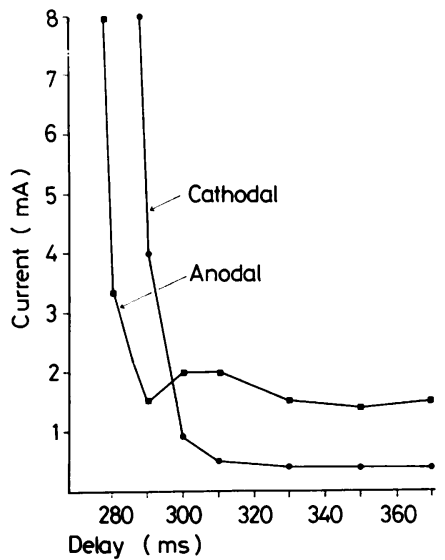

(a)

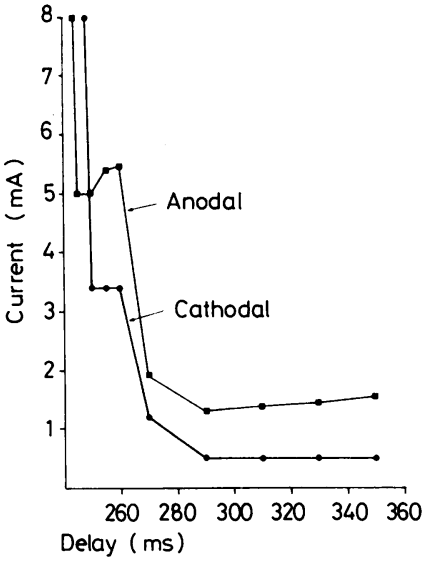

(b)

Fig. 2 (a) Typical unipolar cathodal and anodal strength-interval curves obtained during an acute study in a patient with a unipolar electrode (Medtronic 6907; surface area $11 \mathrm{~mm}^{2}$ ). The ordinate represents the excitation current threshold in milliamperes and the abscissa the delay of the test stimulus as measured from the heart rate determining stimulus. Note that the anodal refractory periods are shorter than cathodal for most stimulus currents. (b) Atypical unipolar cathodal and anodal strength-interval curves obtained during an acute study on a patient with a 6097 electrode. 


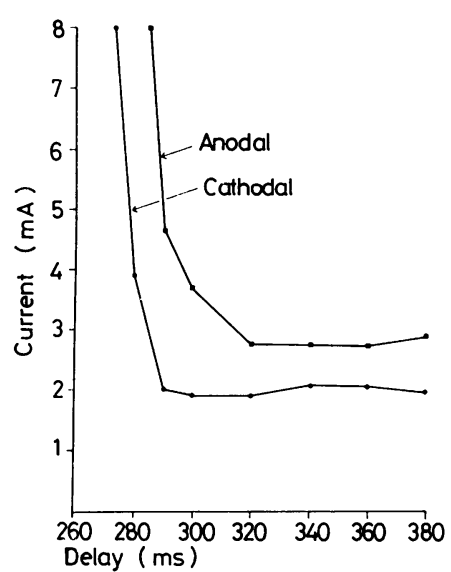

(a)

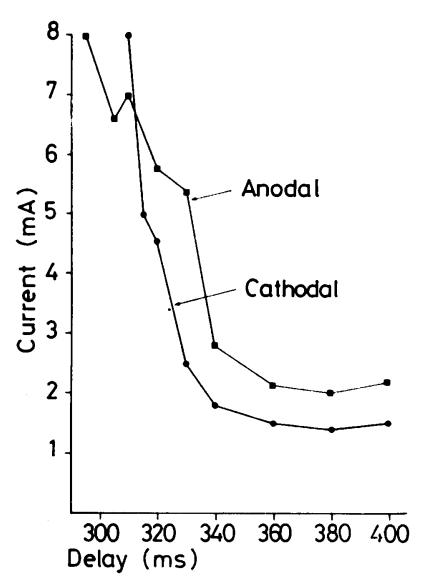

(b)

Fig. 3 (a) Typical unipolar cathodal and anodal strength-interval curves obtained during a chronic study in a patient with a 33-monthold unipolar electrode ( $2 \mathrm{~mm}$ electrode; surface area $\left.=12 \mathrm{~mm}^{2}\right)$. Note the longer anodal refractory periods. (b) Atypical unipolar cathodal and anodal strength-interval curves obtained during a chronic study with a $2 \mathrm{~mm}$ electrode.

Table 2 Difference between unipolar cathodal and anodal refractory periods $(\triangle R P)$ determined in acute and chronic studies

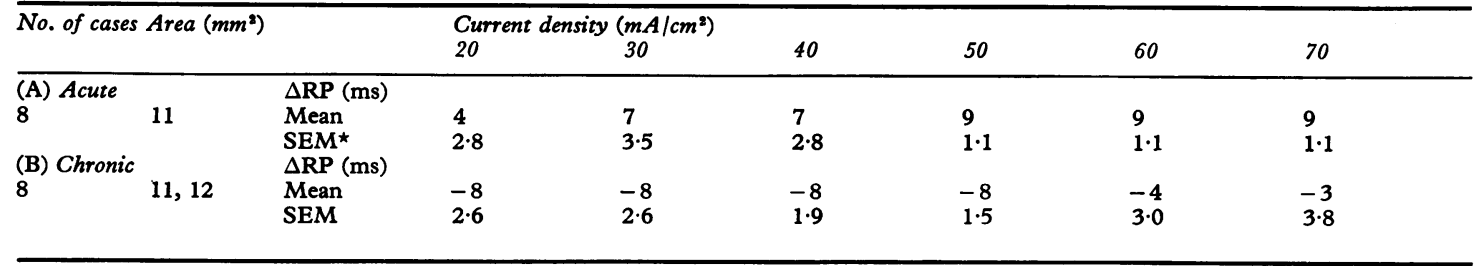

$\star S E M=$ Standard error of the mean.

tory periods were of greater duration than cathodal by an average of 8 to 9 milliseconds. The characteristic 'dip', which represents a narrow region early in the cardiac cycle during which the anodal current threshold is significantly less than in the subsequent interval (Van Dam et al., 1956; Cranefield et al., 1957), was observed in all acute (Fig. 2) and in only 1 of the 9 chronic studies (Fig. 3b).

\section{(b) BIPOLAR AND UNIPOLAR}

\section{STRENGTH-INTERVAL CURVES}

Bipolar, unipolar distal cathodal, and unipolar proximal anodal strength-interval curves were plotted in 22 acute studies. Ten were obtained using the Medtronic model 6901 electrode (tip surface area $11 \mathrm{~mm}^{2}$ and proximal $48 \mathrm{~mm}^{2}$ ) and 12 with the temporary $4 \mathrm{~F}$ Cordis electrode (proximal and the distal areas equal, each 12.5 $\mathrm{mm}^{2}$ ). The results from the 2 studies were very different. With 9 of 10 model 6901 electrodes (90\%) the bipolar and unipolar cathodal refractory periods were equal, as the bipolar strength-interval curve was unaffected by proximal anodal stimulation because of its high excitation threshold and therefore followed the lower of the unipolar distal cathodal and proximal anodal strength-interval curves(Fig.4). In 7 of the 12 cases $(58 \%)$ with temporary electrodes, the bipolar refractory periods were significantly shorter than unipolar cathodal because of low anodal excitation thresholds at the proximal electrode. Thus, in the case shown in Fig. 5a, at a delay shorter than $285 \mathrm{~ms}$ the anodal threshold was lower than the cathodal so that bipolar excitation occurred from the proximal anode to yield equal anodal and bipolar refractory periods. In all 7 cases the 'dip' in the anodal strength-interval curve caused the earlier bipolar excitation, with a 9 ms mean difference between cathodal and bipolar refractory periods at various current densities 


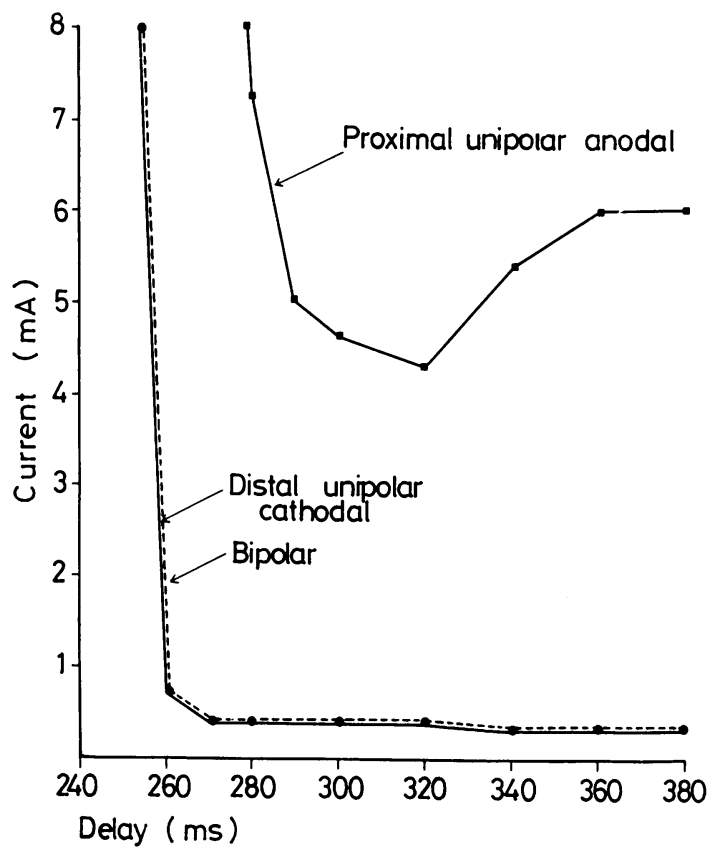

Fig. 4 Unipolar distal cathodal, unipolar proximal anodal, and bipolar strength-interval curves obtained during an acute study in a patient with a 6901 bipolar electrode (case 29). Note that the bipolar and unipolar cathodal curves coincide.
(Table 3 ). With the remaining 5 temporary electrodes (42\%), equal duration cathodal and bipolar refractory periods existed up to $9 \mathrm{~mA}$ as anodal excitation could not be elicited early in the cardiac cycle (Fig. 5b). The only arrhythmia produced by premature stimulation close to the refractory period was a single unstimulated premature contraction in 2 cases.

In chronic studies with bipolar electrodes, cathodal and bipolar strength-interval curves obtained were similar to those obtained in the acute studies with permanent electrodes. Cathodal and bipolar refractory periods were equal in 9 of the 10 cases (90\%) (Fig. 6a). In 7 of the 10 cases, anodal stimulation up to $8 \mathrm{~mA}$ did not initiate excitation at the proximal electrode. With only one model 6901 electrode was the bipolar refractory period shorter than the cathodal (Fig. 6b).

\section{Discussion}

Animal experiments and clinical experience indicate that the probability of inducing an arrhythmia in a vulnerable myocardium is increased by increasing prematurity of a suprathreshold stimulus (Bilitch et al., 1967; Mehra et al., 1977). The present 'acute' study shows that greater prematurity of stimulation occurs with a bipolar stimulus than with a unipolar cathodal stimulus with temporary

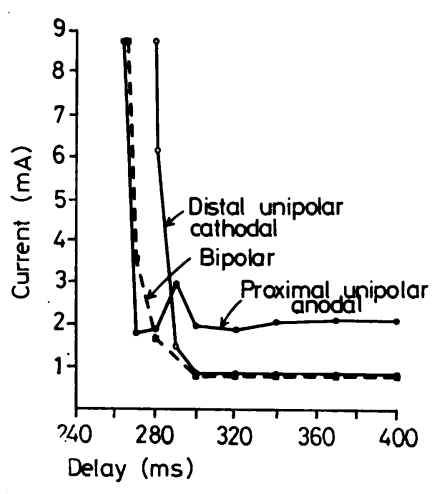

(a)

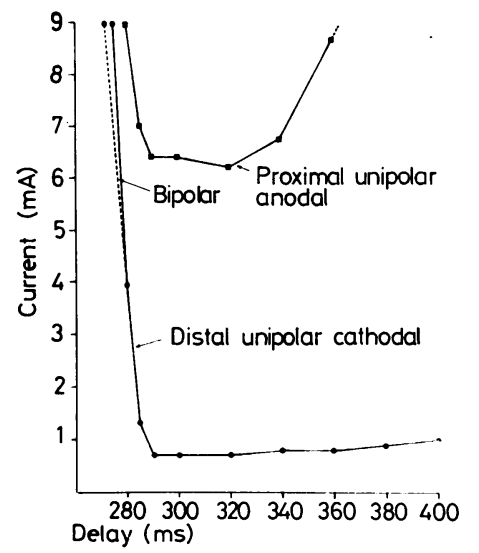

(b)

Fig. 5 (a) Unipolar distal cathodal, unipolar proximal anodal, and bipolar strength-interval curves obtained during an acute study in a patient with a temporary bipolar electrode (case 39). The bipolar and unipolar anodal refractory periods are equal and shorter than unipolar cathodal. (b) Strength-interval curves determined with the same electrode in another patient (case 35). In this case stimulation at the proximal anode does not shorten the bipolar refractory period. 
Table 3 Difference between cathodal and bipolar refractory periods $(\triangle R P)$ determined in patients with temporary electrodes

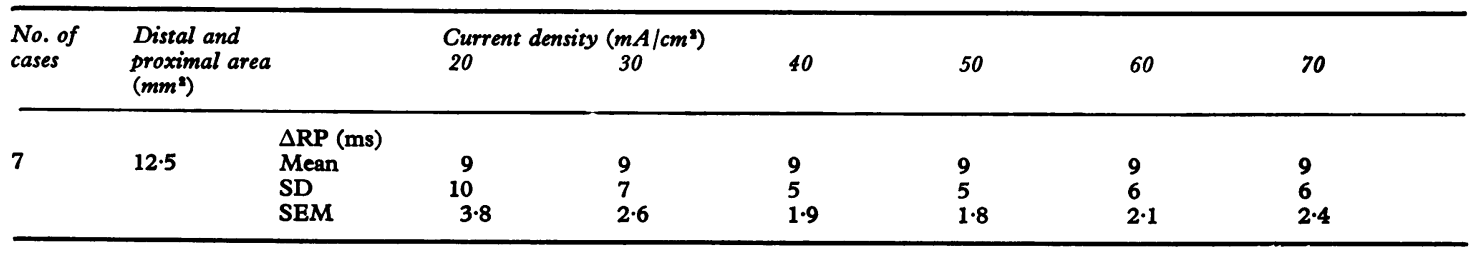

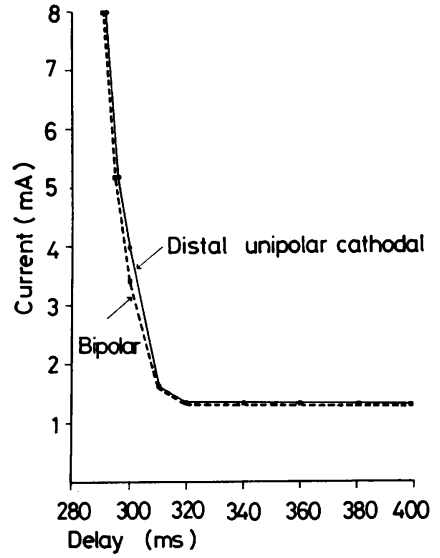

(a)

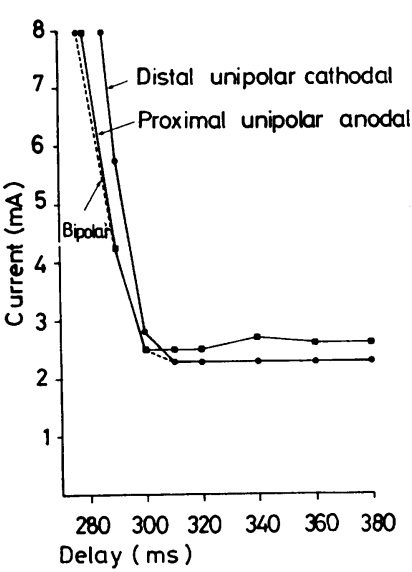

(b)

Fig. 6 (a) Typical strength-interval curves obtained during a chronic study in a patient with a 6901 bipolar electrode. Excitation could not be elicited with anodal stimulation from the proximal electrode site. (b) An atypical case with a 6901 electrode (case 11). Note that the bipolar and anodal refractory periods are shorter than cathodal.

electrodes which have equal surface area cathode and anode (each $12.5 \mathrm{~mm}^{2}$ in this instance). With such electrodes, shorter bipolar refractory periods were obtained in 7 of 12 cases, as a result of earlier anodal stimulation. In 10 acute and 8 chronic studies with permanent electrodes, in which the anodal surface area was 4 to 4.5 times the cathodal, shorter bipolar refractory periods were observed in only one patient in each group. The difference between temporary and permanent electrodes is statistically significant $(P<0.05)$.

The differences between strength-interval curves of the various bipolar electrodes can be explained on the basis of the strength-interval curves determined with unipolar electrodes. In 7 of 12 cases with temporary bipolar electrodes, anodal and cathodal curves were similar to those obtained with unipolar electrodes. In both, shorter anodal refractory periods and the 'anodal dip' were present. In the others ( 5 of 12) the anodal refractory periods were longer. This may be the result of a large tissue-electrode separation which can increase the stimulus current required for threshold, resulting in a shift of the anodal strength-interval curve upward and making the anodal refractory periods longer than cathodal. The longer anodal refractory period found in most acute and chronic studies with permanent electrodes was probably caused by the 4.4 times larger anodal than cathodal surface area. Even when the 2 surface areas were equal in some permanent bipolar electrodes, unipolar chronic strength-interval curves show that the anodal refractory period would still be expected to be longer than the cathodal.

\section{DESIGN OF SAFER PACEMAKER SYSTEMS}

The 7 temporary electrodes in which greater prematurity of stimulation occurred with bipolar rather than with cathodal stimulation could be made safer by increasing the duration of the bipolar refractory period so that it is equal to the cathodal. As current density determines excitation threshold (Furman et al., 1975), this can be accomplished by an increase of the anodal surface area. To make 
bipolar and cathodal refractory periods equal up to $8 \mathrm{~mA}$ of stimulus current the minimum desirable ratio of anodal to cathodal surface area was calculated to be between $1 \cdot 6$ and $4 \cdot 2$. Another way of avoiding the problem of shorter bipolar refractory periods is to move the anode away from the ventricle (Preston, 1974), but this solution may cause problems related to the position of the indifferent terminal.

In only 2 out of 20 acute and chronic studies with permanent electrodes were the bipolar refractory periods shorter than cathodal. In order to make the refractory periods equal with stimulus currents up to $8 \mathrm{~mA}$ in these cases, the anodal surface area would have to be at least 7.0 times the cathodal in an acute study and 6.6 in a chronic study. All these results indicate that an anodal to cathodal surface area ratio of 5 to 7 is desirable for the design of safe temporary and permanent bipolar electrodes.

Other factors also affect the duration of the absolute refractory period and hence the maximum prematurity of a suprathreshold stimulus. Strength- interval curves indicate that lower current densities and short pulse duration stimuli would decrease the probability of precipitating arrhythmias by increasing the shortest stimulus coupling interval (Brooks et al., 1955). The maximum stimulus prematurity with suprathreshold stimuli is also significantly influenced by the time elapsed since electrode insertion, probably as a result of the development of inexcitable tissue around the electrode, which increases the effective surface area and reduces the current density in the excitable tissue (Roy et al., 1968; Tarjan, 1973; Furman et al., 1975). In our chronic studies, the cathodal refractory periods at $70 \mathrm{~mA} / \mathrm{cm}^{2}$ and 80 beats/ minute were $296 \pm 19 \mathrm{~ms}$ as opposed to $268 \pm$ $27 \mathrm{~ms}$ in acute studies with permanent electrodes $(\mathrm{P}<0.05)$.

\section{DOCUMENTED CASES OF VENTRICULAR \\ FIBRILLATION AND TACHYCARDIA}

The data presented help to explain the 30 documented (with the onset illustrated) cases of pace-

Table 4 Documented cases of arrhythmias induced by pacemaker stimuli

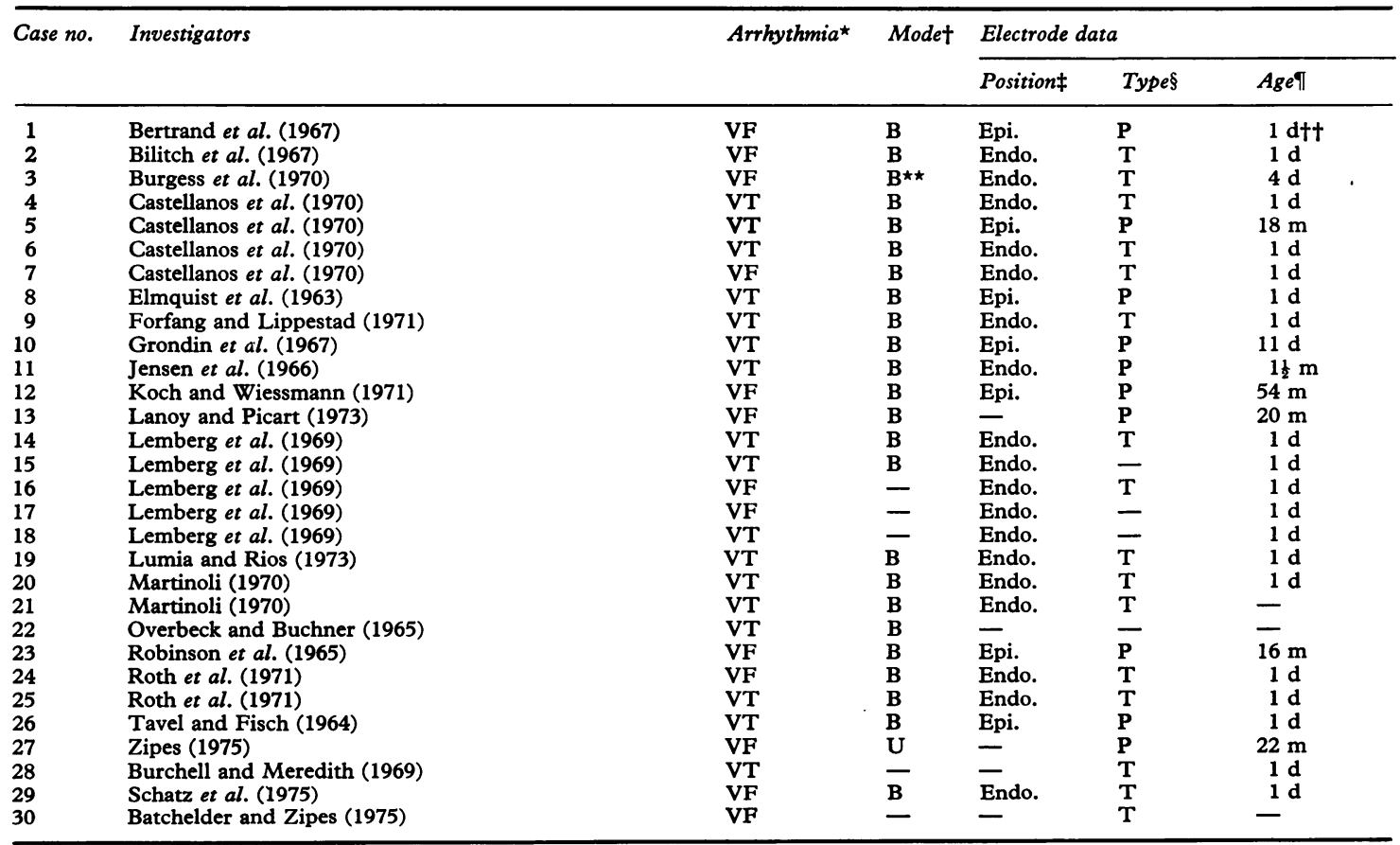

Key:

$\star$ VF, ventricular fibrillation; VT, ventricular tachycardia.

† B, bipolar; U, unipolar cathodal.

$\ddagger$ Endo., endocardial electrode; Epi., epicardial electrode.

$\S \mathbf{P}$, permanent electrode; $T$, temporary electrode.

ๆ Time since electrode implantation, $\mathrm{d}$ : days; $\mathrm{m}$ : months

$\star \star$ Personal communication.

t+ $1 \mathrm{~d}$ indicates less than or equal to 1 day. 
maker induced ventricular tachycardia or fibrillation. The electrode type was mentioned in 25 of these 30 cases, and was bipolar in all except one (Table 4). It is quite likely that these are only a small portion of the total number of such occurrences. Of the 25 episodes, 13 occurred with temporary endocardial electrodes, almost all of which have equal area cathode and anode. Temporary electrodes are commonly used during acute myocardial infarction, but even in these patients use of the bipolar rather than the unipolar mode of stimulation may have been the important factor in inducing arrhythmias. The possible role of bipolar pacing is further emphasised as 8 of 10 cases of ventricular fibrillation/ tachycardia with permanent pacemakers occurred with epicardial electrodes with equal area cathode and anode. Of the remaining 2, 1 occurred with a unipolar cathodal and the other with a bipolar endocardial electrode. In all the documented cases, a pacemaker stimulus from an asynchronous or a malfunctioning demand pacemaker initiated the arrhythmia when it fell on the $T$ wave of an intrinsic beat. Another potentially dangerous situation can arise when a demand pacemaker is switched on. The first stimulus (which in many models does not follow a sensed cardiac cycle) may inadvertently fall within the vulnerable period and precipitate arrhythmias as in cases 19,28 , and 29 (Table 4).

\section{References}

Batchelder, J. E., and Zipes, D. P. (1975). Treatment of tachycardias by pacing. Archives of Internal Medicine, 135, 1115-1124.

Bertrand, M., Cabrol, C., Guiradon, G., Conso, C., and Léon, N. (1967). Fibrillation ventriculaire apres implantation de stimulateur interne. Presse Médicale, 75, 1455-1457.

Bilitch, M., Cosby, R. S., and Cafferky, E. A. (1967). Ventricular fibrillation and competitive pacing. New England Fournal of Medicine, 276, 598-604.

Brooks, C. McC., Hoffman, B. F., Suckling, E. E., and Orias, O. (1955). Excitability of the Heart, pp. 137-146. Grune and Stratton, New York and London.

Burchell, H. B., and Meredith, J. (1969). Management of cardiac tachyarrhythmias with cardiac pacemakers. Annals of the New York Academy of Sciences, 167, 546-556.

Burgess, M. J., Grossman, M., and Abildskov, J. A. (1970). Fibrillation threshold of a patient with myocardial infarction treated with a fixed-rate pacemaker: case report. American Heart fournal, 80, 112-115.

Castellanos, A., Jr., Lemberg, L., Arcebal, A. G., Berkovits, B. V., and Hernandez-Pierotti, O. (1970). Repetitive firing produced by pacemaker stimuli falling after the $\mathrm{T}$ wave. American fournal of Cardiology, 25, 247-251.

Castellanos, A., Jr., Lemberg, L., Jude, J. E., and Berkovits, B. V. (1966). Repetitive firing occurring during synchronized electrical stimulation of the heart. Fournal of Thoracic and Cardiovascular Surgery, 51, 334-340.

Chatterjee, K., Davies, G., Harris, A., and Leatham, A.
(1970). Fall of endocardial potentials after acute myocardial infarction. Lancet, 1, 1308-1312.

Cranefield, P. F., Hoffman, B. F., and Siebens, A. A. (1957). Anodal excitation of cardiac muscle. American fournal of Physiology, 190, 383-390.

Elmquist, R., Landergren, J., Patterson, S. O., Senning, A., and William-Olsson, G. (1963). Artificial pacemaker for treatment of Adams-Stokes syndrome and slow heart rate. American Heart fournal, 65, 731-748.

Forfang, K., and Lippestad, C. T. (1971). Pacemakerinduserte arytmier. Nordisk Medicin, 86, 893-897.

Furman, S., Hurzeler, P., and Parker, B. (1975). Clinical thresholds of endocardial stimulation: a long term study. Fournal of Surgical Research, 19, 149-155.

Grondin, P., Lepage, G., Karamehmet, A., Castonguay, Y., and Meere, C. (1967). Pacemaker-induced repetitive firing: report of two cases. Canadian Medical Association fournal, 96, 1477-1479.

Jensen N. K., Schmidt, T., Garamella, J. J., Lynch, M. F., and Peterson, C. A. (1966). Intracavitary cardiac pacing. fournal of the American Medical Association, 195, 916-918.

Koch, V. R., and Wiessmann, B. (1971). Kammerflimmern durch hertzschrittmacher. Zeitschrift für Kreislaufforschung, 60, 842-850.

Lanoy, M., and Picart, N. (1973). Fibrillation ventriculaire declenchée par un pacemaker a rythme fixe implanté depuis 20 mois. Acta Cardiologica, 28, 208-213.

Lemberg, L., Castellanos, A., Jr., Arcebal, A. G., Berkovits, B. V., and Hernandez-Pierretli, O. (1969). Systolic and diastolic pacemaker induced repetitive firing in the human heart. Fournal of Electrocardiology, 2, 353-362.

Lemberg, L., Castellanos, A., Jr., and Berkovits, B. V. (1965). Pacemaking on demand in A-V block. Fournal of the American Medical Association, 191, 12-14.

Lumia, F. J., and Rios, J. C. (1973). Temporary transvenous pacemaker therapy: an analysis of complications. Chest, 64, 604-608.

Martinoli, E. (1970). Tachiaritmia ventricolare da pacemaker. Minerva Medica, 61, 5420-5424.

Mehra, R., Furman, S., and Crump, J. F. (1977). Vulnerability of the mildly ischemic ventricle to cathodal, anodal and bipolar stimulation. Circulation Research, 41, 159-166.

Overbeck, W., and Buchner, C. (1965). Indikation und operative technik bei der implantation kunstlicher schrittmacher. Lagenbecks Archiv für klinische Chirurgie, 313, 583-591.

Preston, T. A. (1973). Anodal stimulation as a cause of pacemaker induced ventricular fibrillation. American Heart fournal, 86, 366-372.

Preston, T. A. (1974). A new temporary pacing catheter with improved sensing and safety characteristics. American Heart fournal, 88, 289-293.

Robinson, D. S., Falsetti, H. L., Wheeler, D. H., Miller, D. B., and Amidon, E. L. (1965). Ventricular fibrillation associated with two functioning implanted cardiac pacemakers. American fournal of Cardiology, 15, 397-400.

Roth, O., Zinny, M. Z., Lyall, S. S., and Chrystal, L. (1971). Dangers of pacemakers in acute myocardial infarction. Connecticut Medicine, 35, 744-753.

Roy, O. A.. Heggtveit, H. A., and Waddel, W. G. (1968). Electrical and pathological observations on the response of the canine heart to cardiac pacing (abstract). British fournal of Surgery, 55, 861-862.

Schatz, J. W., Wiener, L., and Brest, A. N. (1975). Pacemaker "nonsense". American Heart fournal, 90, 677-678.

Tarjan, P. (1973). Engineering aspects of implantable pacemakers. In Cardiac Pacemaking, p. 54, ed P. Samet. Grune and Stratton, New York.

Tavel, M., and Fisch, C. (1964). Repetitive ventricular arrhythmia resulting from artificial internal pacemaker. 
Circulation, 30, 493-500.

Van Dam, R. T., Durrer, D., Strackee, J., and van der Tweel, L. H. (1956). The excitability cycle of the dog's ventricle determined by anodal, cathodal and bipolar stimulation. Circulation Research, 4, 196-204.

Wiggers, C., and Wegria, R. (1940). Ventricular fibrillation due to single localized induction and condenser shocks applied during the vulnerable phase of the ventricular systole. American fournal of Physiology, 128, 500-505.
Zipes, D. (1975). Electrophysiological mechanisms involved in ventricular fibrillation. Circulation, 51 and 52, Suppl. III, 120-130.

Requests for reprints to Dr Seymour Furman, Cardiothoracic Service, Division of Surgery, Montefiore Hospital and Medical Center, Bronx, New York 10467, USA. 